\title{
ANTHROPOMETRICAL CHARACTERISTICS STRUCTURE TO THE 16-YEAR-OLD MALE STUDENTS
}

\author{
Agron Thaqi ${ }^{i}$ \\ University for Business and Technology, \\ Department of Sport and Movement Science, \\ 10000 Pristina, Kosovo
}

\begin{abstract}
:
The aim of the study is to determine the structure of some anthropometrical characteristics of children aged 16, living in Kosovo. The research was conducted on a sample of 110 male students of high school "Fehmi Lladrovci" in Gllogoc, the Republic of Kosovo. The sample of variable held eighteen anthropometric measures: four variables to estimate the dimensionality of the longitudinal skeleton, four variables to estimate the dimensionality of the transversal skeleton, four variables to estimate the volume of the body, four variables to estimate the skin folds of the body, body weight, and body mass index. The calculation of the data was made by using the SPSS 24 program. All morphological indicators have displayed different parameters that ranged from the lowest to the highest levels. The correlation analysis show that the coefficients of morphological variables are curved and appear as a homogeneous group with a high intercorrelation at the coefficient level of $(p=0.01)$. Factor analysis has shown three latent factors, the first latent factor that has appeared is the anthropometric factor composed of longitudinal dimensionality, transversal dimensionality and body perimeter factors of skeleton. The second latent factor is composed of the skin folds, and the third factor is the anthropometric factor composed of body weight and body mass index.
\end{abstract}

Keywords: anthropometry, basic parameters, correlation, factor analysis

\section{Introduction}

Anthropometry has a great tradition and importance in sports sciences. Throughout history, different terms have been used in terms of anthropometry, such as: dynamic anthropometry, sports anthropometry, biometrics, physiological anthropometry, anthropometric, kinanthropometry etc., by various scientists (Koley, 2006). Anthropometric measurement was the first type of testing used in physical education in

${ }^{\text {i Correspondence: email agron.thaqi@ubt-uni.net }}$ 
the world. Fifty specific measurements were recommended by the American Association for the Advancement of Physical Education (A. Thirumagal, 2013). Anthropometry is also defined as the scientific procedure and process of obtaining surface for anatomical dimensional measurements such as lengths, breadths, girths and skinfolds of the human body by means of specialist equipment (Stewart, 2010).

Quantifying body composition plays a key role in monitoring performance and training in all athletes, because body composition may influence athletes' performance (Thomas, Erdman and Burke, 2016). Anthropometric data should be collected regularly and provided as a standard reference for preliminary health monitoring, based on the World Health Organization (WHO). Anthropometric characteristics are one of the most important factors in most sports branches to indicate whether an athlete can be competitive in the highest level in that sport (Bourgois J. et al. 2002).

It is already known that anthropometric data on the general population are very important to determine the physical dimensions of the workspace, various equipment and clothing that suit the user as well as to avoid a physical discrepancy between the dimensions of products and equipment and corresponding dimensions of different user (Bridger R. S. 1995).

The aim of the study is to determine the structure of some anthropometrical characteristics of male children aged 16 years old. So, based on this goal, this study aims to determine the anthropometric status of 16-year-old male children living in the Municipality of Gllogoc, the Republic of Kosovo.

\section{Methods}

One hundred and ten male students aged 16 years, were tested for their body composition. These children were students of "Fehmi Lladrovci" high school from Glogoc, the Republic of Kosovo.

Anthropometric measurements were measured on a same day for each student in same time to avoid technical error with a criterion anthropometrics accredited by ISAK (ISAK, 1986). During the measurement, students wore only light clothing and without shoes. For the purpose of this study 18 morphological measures have been taken: four variables to estimate the dimensionality of the longitudinal skeleton (Height, Sitting Height, Arm length and Leg length), four variables to estimate the dimensionality of the transversal skeleton (Shoulder width, Pelvis width, Wrist breadth and Knee breadth), four variables to estimate the volume of the body (Arm circumference, Chest circumference, Thigh circumference and Calf girth), four variables to estimate the skin folds of the body (Triceps skinfold, Abdominal skinfold, Subscapular skinfold and Calf skinfold), body weight and body mass index. Body height was measured by the "Martin anthropometer" and the data was read with an accuracy of $0.1 \mathrm{~cm}$. The body weight and body mass index were measured with medical scales (Tanita BC $545 \mathrm{~N}$ Innerscan Segmental Personal Body Analysis) and the data was read with an accuracy of $0.1 \mathrm{~kg}$. Skin fold thickness were measured with a skinfold caliper. Anthropometric tape was used for measuring girth, while sliding caliper was used to measure bone diameter. 
Then, the basic statistical parameters such as arithmetic mean, standard deviation, minimum and maximum values of body dimensions were calculated. Also, a simple Pearson correlation between all parameters was calculated. The factor analysis method applied in this research was used to determine the groups of parameters (factors) characterizing the body constitution of young male students.

\section{Results}

Table 1: Descriptive statistical parameters of anthropometric variables

\begin{tabular}{|l|c|c|c|c|c|c|c|}
\hline & $\mathbf{N}$ & Minimum & Maximum & Mean & Std. Deviation & Skewness & Kurtosis \\
\hline H & 110 & 162.0 & 195.0 & 174.027 & 6.2350 & .603 & .199 \\
\hline STH & 110 & 116.0 & 135.0 & 124.073 & 3.5406 & .441 & .642 \\
\hline AL & 110 & 65.0 & 83.0 & 76.023 & 3.6305 & -.472 & .141 \\
\hline LL & 110 & 83.0 & 110.0 & 96.959 & 4.4763 & .098 & .944 \\
\hline SHW & 110 & 33.5 & 45.0 & 39.355 & 2.2060 & -.196 & .359 \\
\hline PW & 110 & 26.0 & 37.0 & 31.108 & 2.0567 & .413 & .512 \\
\hline WB & 110 & 5.0 & 6.8 & 5.735 & .3219 & .441 & .843 \\
\hline KB & 110 & 8.0 & 12.0 & 9.785 & .7432 & .630 & 1.067 \\
\hline AC & 110 & 19.0 & 37.0 & 25.995 & 3.4057 & .593 & .285 \\
\hline CHC & 110 & 70.0 & 110.0 & 86.023 & 7.4219 & .400 & .259 \\
\hline THC & 110 & 33.0 & 65.0 & 47.245 & 5.7985 & .365 & .291 \\
\hline CG & 110 & 26.0 & 42.5 & 34.023 & 3.1312 & .136 & .306 \\
\hline TS & 110 & 4.0 & 27.0 & 9.182 & 4.4561 & $\mathbf{1 . 6 2 2}$ & $\mathbf{3 . 0 5 9}$ \\
\hline As & 110 & 5.0 & 37.0 & 12.227 & 7.7088 & $\mathbf{1 . 6 8 1}$ & $\mathbf{2 . 3 3 1}$ \\
\hline SS & 110 & 4.0 & 23.0 & 7.673 & 3.5300 & $\mathbf{2 . 0 5 1}$ & $\mathbf{4 . 6 5 9}$ \\
\hline CS & 110 & 4.0 & 24.0 & 9.455 & 4.4177 & $\mathbf{1 . 2 3 8}$ & 1.145 \\
\hline W & 110 & 40.30 & 98.00 & 62.9963 & 11.67029 & .598 & -.005 \\
\hline BMI & 110 & 13.9 & 30.9 & 20.638 & 3.6077 & .813 & .256 \\
\hline
\end{tabular}

H: Height $(\mathrm{cm})$, SH: Sitting height $(\mathrm{cm})$, AL: Arm length $(\mathrm{cm})$, LL: Leg length $(\mathrm{cm})$, SHW: Shoulder width $(\mathrm{cm})$, PW: Pelvis width $(\mathrm{cm})$, WB: Wrist breadth $(\mathrm{cm})$, KB: Knee breadth $(\mathrm{cm})$, AC: Arm circumference $(\mathrm{cm})$, CHC: Chest circumference $(\mathrm{cm})$, THC: Thigh circumference $(\mathrm{cm})$, CG: Calf girth $(\mathrm{cm})$, TS: Triceps skinfold (mm), AS: Abdominal skinfold (mm), SS: Subscapular skinfold (mm), CS: Calf skinfold $(\mathrm{mm}), \mathrm{W}$ : Weight $(\mathrm{kg})$, BMI: Body mas index $\left(\mathrm{kg} / \mathrm{m}^{2}\right)$.

Skewness $>1$ - positive skew, \pm 0 - normal, $<-1$ - negative skew Kurtosis $>+2$ leptokurtic distribution, \pm 2 normal (mesokurtic) distribution, $<-2$ platykurtic distribution $\mathrm{p}$ : sig. $\left(\mathrm{p}<0.05^{*}\right)$.

In Table 1 are shown basic statistic parameters of anthropometric characteristics, including arithmetic average, minimal result, maximal result, standard deviation, Skewness, Kurtosis. From this table, we can conclude that the values of all variables have a major difference between the $\min$ and $\max$ results. Standard deviations for anthropometric tests: (W, AS, CHC, H) are in a high level, while other anthropometric tests at a low level. As for the basic parameters, (Skewness), we can see that the results of variables: (TS, AS, SS, CS) have shown e positive distribution, all the other variables have shown e normal distribution. Whereas, regarding the basic parameters, anthropometric statistics, statistical method of asymmetry coefficient (Kourtosis), we notice that the 
results of anthropometric variables: (TS, AS, SS) have shown leptokurtic distribution, the other variables have shown a normal (mesokurtic) distribution.

Table 2: Analysis of correlation between anthropometric variables

\begin{tabular}{|c|c|c|c|c|c|c|c|c|c|c|c|c|c|c|c|c|c|c|}
\hline & $\mathbf{H}$ & $\mathrm{SH}$ & $\mathrm{AL}$ & LL & SHW & PW & WB & KB & $\mathrm{AC}$ & CHC & THC & CG & TS & AS & S S & CS & $\mathbf{W}$ & BMII \\
\hline $\mathrm{H}$ & 1 & & & & & & & & & & & & & & & & & \\
\hline $\mathrm{SH}$ & $.674^{* *}$ & 1 & & & & & & & & & & & & & & & & \\
\hline $\mathrm{AL}$ & $.704^{*}$ & $.433^{* *}$ & 1 & & & & & & & & & & & & & & & \\
\hline LL & $.696^{\prime \prime}$ & $.367^{\prime \prime}$ & $.610^{* *}$ & 1 & & & & & & & & & & & & & & \\
\hline SHW & $.403^{\prime \prime \prime}$ & $.503^{\prime \prime}$ & $.358^{\prime \prime}$ & $.217^{\circ}$ & 1 & & & & & & & & & & & & & \\
\hline $\mathrm{PW}$ & $.395^{* \prime}$ & $.428^{\prime \prime}$ & $.353^{\prime \prime}$ & $.234^{\circ}$ & $.562^{* *}$ & 1 & & & & & & & & & & & & \\
\hline WB & $.416^{\prime \prime}$ & $.507^{* *}$ & $.307^{4}$ & $.237^{\circ}$ & $.526^{\prime \prime}$ & $.556^{6 *}$ & 1 & & & & & & & & & & & \\
\hline KB & .109 & .161 & .095 & .089 & $.394^{*}$ & $.391^{* *}$ & $.334^{* *}$ & 1 & & & & & & & & & & \\
\hline AC & .164 & $.339^{\prime \prime}$ & .096 & .012 & $.558^{* 4}$ & $.583^{* *}$ & $.465^{* *}$ & $.538^{\prime \prime}$ & 1 & & & & & & & & & \\
\hline CHC & $.267^{\prime \prime}$ & $.378^{* 1 *}$ & $.196^{*}$ & .072 & $.538^{* *}$ & $.545^{*}$ & $.433^{* *}$ & $.505^{*}$ & $.809^{* *}$ & 1 & & & & & & & & \\
\hline THC & .120 & $.381^{*}$ & -026 & .015 & $.501^{*}$ & $.528^{* *}$ & $.385^{*}$ & $.590^{*}$ & $.780^{*}$ & $.744^{*}$ & 1 & & & & & & & \\
\hline CG & $.226^{*}$ & $.389^{* \prime \prime}$ & .103 & .087 & $.542^{* *}$ & $.622^{*}$ & $.452^{* *}$ & $.574^{* 4}$ & $.816^{* 6}$ & $.759^{\prime \prime}$ & $.786^{\prime \prime}$ & 1 & & & & & & \\
\hline TS & .088 & $.214^{*}$ & .043 & .011 & $.409^{* *}$ & $.574^{* *}$ & $.247^{* *}$ & $.587^{\prime \prime}$ & $.756^{*}$ & $.668^{\prime \prime}$ & $.661^{*}$ & $.714^{*}$ & 1 & & & & & \\
\hline AS & .045 & .158 & .011 & .007 & $.314^{* *}$ & $.541^{* *}$ & $.196^{*}$ & $.572^{\prime \prime}$ & $.726^{*}$ & $.643^{\prime \prime}$ & $.631^{*}$ & $.693^{* *}$ & $.895^{* *}$ & 1 & & & & \\
\hline SS & .025 & .162 & -0.007 & -035 & $.352^{* *}$ & $.538^{* \prime \prime}$ & $.242^{*}$ & $.582^{*}$ & $.742^{* *}$ & $.640^{\circ}$ & $.656^{\prime \prime}$ & $.685^{\prime \prime}$ & $.914^{* *}$ & $.907^{*}$ & 1 & & & \\
\hline CS & .059 & $.188^{*}$ & .028 & 0.026 & $362^{* *}$ & $.558^{* \prime}$ & $.200^{*}$ & $.576^{\prime \prime}$ & $.704^{* *}$ & $.625^{*}$ & $.633^{* *}$ & $.711^{*}$ & $.902^{* *}$ & $.848^{* *}$ & $.831^{\prime \prime}$ & 1 & & \\
\hline W & $.399^{* \prime \prime}$ & $.517^{\prime \prime}$ & $.278^{* \prime}$ & .148 & $.650^{* *}$ & $.701^{*}$ & $.576^{* *}$ & $.581^{*}$ & $.881^{* \prime \prime}$ & $.867^{7 *}$ & $.805^{\circ *}$ & $.861^{*}$ & $.783^{* *}$ & $.742^{* *}$ & $.757^{\prime \prime}$ & $.721^{* *}$ & 1 & \\
\hline BMI & -.006 & $.265^{\prime \prime}$ & .003 & -086 & $.547^{*}$ & $.649^{* * *}$ & $.452^{* *}$ & $.627^{\prime \prime}$ & $.828^{* \prime \prime}$ & $.780^{\circ}$ & $.835^{*}$ & $.804^{* \prime}$ & $.777^{*}$ & $.746^{* *}$ & $.785^{*}$ & $.736^{* *}$ & $.859^{* *}$ & 1 \\
\hline \multicolumn{19}{|c|}{ *. Correlation is significant at the 0.05 level (2-tailed). ${ }^{* *}$. Correlation is significant at the 0.01 level (2-tailed). } \\
\hline \multicolumn{19}{|c|}{$\begin{array}{l}\text { H: Height }(\mathrm{cm}) \text {, SH: Sitting height }(\mathrm{cm}) \text {, AL: Arm length }(\mathrm{cm}) \text {, LL: Leg length }(\mathrm{cm}) \text {, SHW: Shoulder width } \\
(\mathrm{cm}) \text {, PW: Pelvis width }(\mathrm{cm}), \text { WB: Wrist breadth }(\mathrm{cm}), \text { KB: Knee breadth }(\mathrm{cm}), \text { AC: Arm circumference }(\mathrm{cm}) \text {, } \\
\text { CHC: Chest circumference }(\mathrm{cm}) \text {, THC: Thigh circumference }(\mathrm{cm}), \text { CG: Calf girth }(\mathrm{cm}) \text {, TS: Triceps skinfold } \\
(\mathrm{mm}) \text {, AS: Abdominal skinfold }(\mathrm{mm}) \text {, SS: Subscapular skinfold }(\mathrm{mm}) \text {, CS: Calf skinfold }(\mathrm{mm}), \text { W:Weight } \\
(\mathrm{kg}) \text {, BMI: Body mass index }(\mathrm{kg} / \mathrm{m} 2) \text {. }\end{array}$} \\
\hline
\end{tabular}

Table 2 shows the coefficients of intercorrelation for all anthropometric variables. As it can be seen, correlation is significant at the 0.01 level between most of variables, but we also have significant correlation coefficients with some coefficients with low correlations.

Table 3: Initial Eigenvalues

\begin{tabular}{|l|c|c|c|c|c|c|c|c|c|}
\hline \multicolumn{2}{|c|}{ Total Variance Explained } \\
\hline Component & \multicolumn{3}{|c|}{$\begin{array}{c}\text { Initial } \\
\text { Eigenvalues }\end{array}$} & \multicolumn{2}{c|}{$\begin{array}{c}\text { Extraction Sums of Squared } \\
\text { Loadings }\end{array}$} & \multicolumn{3}{|c|}{$\begin{array}{c}\text { Rotation Sums of Squared } \\
\text { Loadings }\end{array}$} \\
\cline { 2 - 11 } & Total & $\begin{array}{c}\text { \% of } \\
\text { Variance }\end{array}$ & $\begin{array}{c}\text { Cumulative } \\
\%\end{array}$ & Total & $\begin{array}{c}\% \text { of } \\
\text { Variance }\end{array}$ & $\begin{array}{c}\text { Cumulative } \\
\%\end{array}$ & Total & $\begin{array}{c}\% \text { of } \\
\text { Variance }\end{array}$ & $\begin{array}{c}\text { Cumulative } \\
\%\end{array}$ \\
\hline 1 & 9.656 & 53.647 & 53.67 & 9.656 & 53.647 & 53.647 & 7.515 & 41.749 & 41.749 \\
\hline 2 & 3.133 & 17.408 & 71.05 & 3.133 & 17.408 & 71.055 & 3.632 & 20.177 & 61.927 \\
\hline 3 & 1.129 & 6.272 & 77.37 & 1.129 & 6.272 & 77.327 & 2.772 & 15.401 & 77.327 \\
\hline
\end{tabular}

From Table 3 it is noticed that three Eigenvalues have been extracted or displayed. Which explain $77.3 \%$ of the variance, which is relatively a satisfactory value. 
Table 4: Component Matrix of morphological variables

\begin{tabular}{|l|c|c|c|c|}
\hline & $\mathbf{1}$ & $\mathbf{2}$ & $\mathbf{3}$ & $\mathbf{H}^{\mathbf{2}}$ \\
\hline Height & .306 & .855 & .188 & .859 \\
\hline Sitting height & .463 &. $\mathbf{6 2 5}$ & -.195 & .643 \\
\hline Arm length & .217 & .775 & .303 & .740 \\
\hline Leg length & .137 & .736 & .435 & .750 \\
\hline Shoulder width & $\mathbf{6 4 8}$ & .358 & -.295 & .636 \\
\hline Pelvis width & .745 & .247 & -.005 & .616 \\
\hline Wrist breadth &. $\mathbf{5 3 8}$ & .436 & -.438 & .671 \\
\hline Knee breadth & $\mathbf{. 6 7 6}$ & -.116 & .091 & .478 \\
\hline Arm circumference & .895 & -.113 & -.137 & .833 \\
\hline Chest circumference & $\mathbf{. 8 5 0}$ & .006 & -.123 & .738 \\
\hline Thigh circumference & $\mathbf{. 8 3 8}$ & -.135 & -.218 & .768 \\
\hline Calf girth & $\mathbf{. 8 8 6}$ & -.046 & -.100 & .797 \\
\hline Triceps skinfold & .866 & -.276 & .293 & .911 \\
\hline Abdominal skinfold & $\mathbf{. 8 2 6}$ & -.320 & .338 & .898 \\
\hline Subscapular skinfold &. $\mathbf{8 3 8}$ & -.333 & .269 & .886 \\
\hline Calf skinfold & .822 & -.297 & .297 & .852 \\
\hline Weight & $\mathbf{. 9 6 4}$ & .100 & -.076 & .945 \\
\hline Body mas index & $\mathbf{. 9 0 2}$ & -.237 & -.171 & .899 \\
\hline
\end{tabular}

In the first main component high projections have the variables of transverse skeletal dimensionality: Shoulder width, Pelvis width, Wrist breadth, Knee breadth (.74 - .53), body perimeter factors of the skeleton: Arm circumference, Chest circumference, Thigh circumference, Calf girth (.89 - .83), the skin folds: Triceps skinfold, Abdominal skinfold, Subscapular skinfold, Calf skinfold (.86 - .82), and body weight and body mass index (.96 $-.94)$.

The second component is defined by variables of transverse skeletal dimensionality: Height, Sitting Height, Arm length, Leg length (.85 - .62).

Table 4 also shows the values of the variability $(\mathrm{H} 2)$ where it is seen that generally high variability values are obtained. The highest values were given by the variables: body mass, skinfold dimension, body volume dimension and body length (.94-. 73), while the lowest values were given by the transverse body dimension variables (.67 - .47).

Table 4, also, shows the values of the variability communalities (H2) where it is seen that generally high variability values are obtained. The highest values were given by the variables: body mass, skin fold dimension, body volume dimension and body length (.94-. 73), while the lowest values were given by the transverse body dimension variables $(.67-.47)$.

As we can see in Table 5, we have three factors displayed by the variables included in this study. 
Table 5: Matrix structure of morphological variables (statistically significant factor loads are bold)

\begin{tabular}{|l|c|c|c|}
\hline Pattern Matrix $^{\mathbf{a}}$ & \multicolumn{3}{l|}{} \\
\hline Height & $\mathbf{1}$ & $\mathbf{2}$ & $\mathbf{3}$ \\
\hline Sitting height & -.032 & .836 & -.234 \\
\hline Arm length & -.036 & .408 & -.596 \\
\hline Leg length & .005 & .843 & -.054 \\
\hline Shoulder width & .040 & .894 & .125 \\
\hline Pelvis width & .174 & .144 & -.656 \\
\hline Wrist breadth &. $\mathbf{4 8 2}$ & .258 & -.340 \\
\hline Knee breadth & -.039 & .100 & -.801 \\
\hline Arm circumference & $\mathbf{. 6 5 3}$ & .027 & -.075 \\
\hline Chest circumference & $\mathbf{. 6 8 8}$ & -.106 & -.386 \\
\hline Thigh circumference & $\mathbf{. 6 0 5}$ & -.005 & -.402 \\
\hline Calf girth & $\mathbf{. 6 0 1}$ & -.182 & -.443 \\
\hline Triceps skinfold & $\mathbf{. 6 7 2}$ & -.028 & -.370 \\
\hline Abdominal skinfold & $\mathbf{1 . 0 0 5}$ & .052 & .139 \\
\hline Subscapular skinfold & $\mathbf{1 . 0 2 1}$ & .043 & .216 \\
\hline Calf skinfold & $\mathbf{. 9 9 4}$ & -.013 & .145 \\
\hline Weight & $\mathbf{. 9 8 2}$ & .034 & .165 \\
\hline Body mas index & $\mathbf{. 6 8 2}$ & .112 & -.426 \\
\hline
\end{tabular}

Factor 1 is a combination of: Pelvis width, Knee breadth, body perimeter factors of the skeleton (Arm circumference, Chest circumference, Thigh circumference, Calf girth), Triceps skinfold, Abdominal skinfold, Subscapular skinfold, Calf skinfold and body weight and body mass index (1.0 - .48). It describes body morphology of male students better than factor 2 and 3 what is proved by previously described values and the percentage of variability explained.

Factor 2 is a combination of three parameters: Height, Arm Length, and Leg length (.89 - .83). All those traits are length parameters indicating vertical values of the entire body. This factor was called longitudinal dimension.

Factor 3 is a combination of three parameters : Sitting Height, Wrist breadth and Shoulder width $(.80-.59)$.

Table 6: Component Correlation Matrix

\begin{tabular}{|l|c|c|c|}
\hline Component Correlation Matrix & $\mathbf{1}$ & $\mathbf{2}$ & $\mathbf{3}$ \\
\hline Component & 1.000 & & \\
\hline 1 & .037 & 1.000 & \\
\hline 2 & -.433 & -.287 & 1.000 \\
\hline 3 & &
\end{tabular}

Table 6 shows inter-correlation factors, which may conclude that there is a significant correlation between F1 and F3 (-.433), whereas between F2 and F3 (-.287) low correlation. There is no significant correlation between F1 and F2. 


\section{Discussion}

The results of the study conducted to determine the individual body measures of the16 year old boys are collectively shown in Tables 1-6. As can be seen all variables have a major difference between the minimum and maximum results. Standard deviations for anthropometric tests: W: Weight, As: Abdominal skinfold, CHC: Chest circumference, $\mathrm{H}$ : Height, are in a high level, while other anthropometric tests at a low level. As for the basic parameters, statistical anthropometrics, statistical method of coefficient of asymmetry (Skewness), in this age group tests, we can see that the results of variables: TS: Triceps skinfold, AS: Abdominal skinfold, SS: Subscapular skinfold, CS: Calf skinfold have shown e positive distribution, all the other variables have shown e normal distribution. Whereas, regarding the basic parameters, anthropometric statistics, statistical method of asymmetry coefficient (Kourtosis), in this age group of the tested we notice that the results of anthropometric variables: TS: Triceps skinfold, AS: Abdominal skinfold, SS: Subscapular skinfold) have shown leptokurtic distribution, the other variables have shown a normal (mesokurtic) distribution. Based on research data of Daval, S. Z. et al. (2012). Comparison of anthropometric data for high school male students significant differences were found in weight, stature, shoulder breadth, arm reach forward, forearm-hand length, sitting height, sitting eye height, sitting shoulder height and span (Daval, S. Z. et al. 2012).

Table 2 shows the coefficients of intercorrelation for all anthropometric variables. As it can be seen, correlation is significant at the 0.01 level between most of variables, but we also have significant correlation coefficients with some coefficients with low correlations.

Through factorial analysis of anthropometric peaks, the system of variables is reduced to only a few variables representing latent skeletal dimensions. These latent factors and dimensions obtained in this way can be used for any further analysis. The method of factor analysis is an efficient tool for characterizing anthropometric parameters among children. The analysis of 18 anthropometric parameters allows us to separate three factors of body morphology: a) the anthropometric factor composed of Pelvis width, Knee breadth, body perimeter factors of the skeleton (Arm circumference, Chest circumference, Thigh circumference, Calf girth), the skin folds (Triceps skinfold, Abdominal skinfold, Subscapular skinfold, Calf skinfold), and body weight and body mass index. b) the anthropometric factor composed of the longitudinal dimensionality (High, Arm Length, and Leg length) and the c) the anthropometric factor composed of Sitting Height, Wrist breadth and Shoulder width. The same factor was expressed by the author Isen, A., et al. (2021).

\section{Conclusions}

The method of factor analysis is an efficient tool for characterizing anthropometric parameters among male high school children. The analysis of 18 anthropometric parameters allows us to separate three factors of body morphology: 
a) Skinfold dimension, body perimeter and body mas: Pelvis width, Knee breadth, Arm circumference, Chest circumference, Thigh circumference, Calf girth, Triceps skinfold, Abdominal skinfold, Subscapular skinfold, Calf skinfold and Body weight and Body mass index.

b) Vertical dimension, including: Height, Arm Length, and Leg length,

c) A combination of three parameters: Sitting Height, Wrist breadth and Shoulder width.

These traits should be used in training process estimation and check-up after training changes, as well as sport selection.

\section{Conflicts of Interest}

The author declares that there is no conflict of interest in this manuscript.

\section{About the Author}

Agron Thaqi, currently works as an Asst. Prof. Dr. at the UBT - Higher Education Institution. Sport and Movement Science. Agron does research on motor skills related to soccer, athlete, measuring sports performance, etc.

\section{References}

A. Thirumagal (2013). Challenges of Academic Library Management in Developing Countries, Pages: 10, DOI: 10.4018/978-1-4666-4070-2.ch020.

Bourgois J., Claessens A. L., Vrijens J., Philippaerts R., Renterghem B. V., Thomis M., Janssens M., Loos R., Lefevre J. (2002). Anthropometric characteristics of elite male junior rowers. British Journal of Sports Medicine; 34(3):213-217.

Bridger R. S. (1995). Introduction to ergonomics. Singapore: McGraw-Hill.

Dawal, S. Z., Zadry, H. R., Syed, A., Sharifah, N., Rohim, S. R., Sartika, S. J. (2012). Anthropometric Database for the Learning Environment of High School and University Students. International Journal of Occupational Safety and Ergonomics, 18(4), 461-472. doi:10.1080/10803548.2012.11076953.

ISAK, International Society for the Advancement of Kinanthropometry, 1986, www.isakonline.com.

Iseni, A., Kryeziu, A., Rexhepi, A. (2021). The Structure of Some Anthropometrical characteristics of 15-Year-Old Students UDC: 796.012.1:373.5-057.874(497.721).

Koley S. (2006). New Horizons in Kinanthropometry. New Delhi: Friends Publications.

Stewart, A. D. (2010). Kinanthropometry and Body Composition: a natural home for 3D photonic scanning. J. Sports Sci.28, 455-457.

Thomas, D., Erdman, K., \& Burke, L. (2016). American College of Sports Medicine joint position statement. Nutrition and athletic performance. Medicine and Science in Sports and $\quad$ Exercise, 543-568. https://doi.org/10.1249/MSS.0000000000000852. 
World Health Organization (1995). The Use and Interpretation of Anthropometry; Report of a WHO Expert Committee; Technical Report Series; World Health Organization: Geneva, Switzerland; Volume 854.

Creative Commons licensing terms

Authors will retain the copyright of their published articles agreeing that a Creative Commons Attribution 4.0 International License (CC BY 4.0) terms will be applied to their work. Under the terms of this license, no permission is required from the author(s) or publisher for members of the community to copy, distribute, transmit or adapt the article content, providing a proper, prominent and unambiguous attribution to the authors in a manner that makes clear that the materials are being reused under permission of a Creative Commons License. Views, opinions and conclusions expressed in this research article are views, opinions and conclusions of the author(s). Open Access Publishing Group and European Journal of Physical Education and Sport Science shall not be responsible or answerable for any loss, damage or liability caused in relation to/arising out of conflict of interests, copyright violations and inappropriate or inaccurate use of any kind content related or integrated on the research work. All the published works are meeting the Open Access Publishing requirements and can be freely accessed, shared, modified, distributed and used in educational, commercial and non-commercial purposes under a Creative Commons attribution 4.0 International License (CC BY 4.0). 